\title{
INTERACTION TIME AND BEAM DIAMETER EFFECTS ON THE CONDUCTION MODE LIMIT
}

\author{
Eurico Assuncao ${ }^{1}$, Stewart Williams ${ }^{1}$ and David Yapp ${ }^{1}$, \\ ${ }^{1}$ Welding Engineering Research Centre, Cranfield University, MK43 OAL, United Kingdom
}

\begin{abstract}
Laser welding has two distinctive modes, keyhole and conduction mode. Keyhole mode is characterized by deep penetration and high welding speeds, while conduction mode has higher quality welds with no defects or spatter. This study focuses on the transition from conduction to keyhole mode by increasing power density and using different beam diameters and interaction times. Based upon the results it was possible to evaluate that there is a transition mode between conduction and keyhole mode. The results show that the transition between conduction and keyhole mode is not defined by a single power density value. This transition has a range of power densities that depend on the beam diameter and on the interaction time. This study allows the identification of the power density that limits conduction mode, based on parameters such as beam diameter and interaction time instead of a single power density value independent of these parameters.
\end{abstract}

Key words: Laser welding, keyhole mode, conduction mode

\section{Introduction}

There are two main modes of laser welding, conduction and keyhole[1] with many example applications of these. However the number of applications that use the keyhole mode[2-4] is considerably higher than the number of applications where conduction mode is used[5, 6]. The advantages that conduction mode presents such as no porosity, cracks and undercut in the welds along with the fact that there is no spatter during welding makes this a useful mode[7]. The main difference between conduction and keyhole mode welding is the power density applied to the welding area. In conduction mode the power density applied is insufficient to cause significant vaporization[1, 8, 9]. While in keyhole mode the power density is high enough not only to vaporize material but to open a hole in the melt pool. Despite many studies on these two welding modes the boundaries between them are not clear in terms of processing parameters. For example sometimes the separation between conduction and keyhole welding is described as; if the power density is lower than $10^{6}$ $\mathrm{W} / \mathrm{cm}^{2}$ the weld is in conduction mode, if it is higher than this it occurs in keyhole mode [5, 8-10]. Other definitions based on the power are also used, e.g. if the weld takes place with a laser power, of the order of one kilowatt; it is considered that the weld is in conduction mode [8]. These definitions only rely on the power density or laser power used during the process, completely neglecting other parameters such as the welding speed or the beam diameter used. These definitions also assume that there is a sharp transition between conduction and keyhole mode[ 1,5 , 8-10], meaning that there is no transition 
regime them. The number of studies focused on the transition between conduction mode and keyhole mode is very limited. An example is the study done by Sibillano where he was able to determine the welding mode by studying the plasma/plume emission during welding based on the spectroscopy data [11]. However this study does not relate the welding parameters to the welding mode and relied on the fact that there is a single power density separating conduction mode and keyhole mode. Another study that focused on the transition between conduction and keyhole mode laser welding was carried out by Zhang[12]. In his work he studied the transition between the different welding modes using laser power, focal position and travel speed as his process parameters. During this study he identified three welding mode regimes, Heat conduction welding, stable deep penetration welding and unstable mode welding. The unstable mode welding had been previously identified by Chen[13] and Zhang[14] and it was attributed to thermal focusing $[15,16]$, to an incorrect selection of welding parameters or to welding mode fluctuation. More studies have shown the presence of a regime between conduction mode and keyhole mode[1, 17-20], while other studies just take into account two welding modes[21, 22]. The transition between conduction mode and keyhole mode is somewhat unclear, not only in terms of which and how the different process parameters will influence this transition but also related to the presence or not of a transition mode.

The depth-to-width ratio or aspect ratio is also used to distinguish between conduction and keyhole mode. It is assumed that over a certain ratio value the weld will be in keyhole mode and below it will be in conduction mode[23].
In this paper, the fundamental material interaction parameters of power density and interaction time[1, 9] are used. The specific point energy parameter is also used. The power density is calculated using the following equation,

$$
\text { Power Density }=\frac{}{(\quad)} \text {, }
$$

Where $\mathrm{P}$ is power and $\mathrm{A}_{\text {(Beam) }}$ is the area of the laser beam. Interaction time is calculated based on the following equation;

$$
t_{i}=\frac{d_{b}}{V},
$$

Where $d_{b}$ is the beam diameter and $V$ is the welding speed. The interaction time can be interpreted as the heating time of the process on the centreline of the weld [9].

The specific point energy is calculated based on the following equation;

$$
=\text { Power density } \times \quad(\quad) \times
$$

The use of these parameters allows a like for like comparison between different beam diameters.

The objective of this paper is to investigate the current definition of conduction and keyhole mode and to see if the transition between conduction and keyhole mode is a sharp transition. An evaluation of the beam diameter and interaction time effect on the upper limit of power density for conduction mode is also made. Understanding the effect of these parameters on this limit is important when choosing to use one mode or the other.

\section{Experimental Procedure}

The welds were produced using an IPGYLR8000 fibre laser with a maximum power of 
$8000 \mathrm{~W}$ and a wavelength of $1070 \mathrm{~nm}$. The delivery system consisted of a fibre with a diameter of $300 \mu \mathrm{m}$. a $125 \mathrm{~mm}$ collimating lens and five different focal length lenses. The focusing lenses used and the respective beam diameters in focal position are shown in Table 1. By using different focusing lenses several beam diameters were obtained without defocusing and without altering the laser beam profile.

Table 1 - List of focusing lens used and respective beam diameters in the focal position

\begin{tabular}{|c|c|}
\hline Focusing Lens & $\begin{array}{c}\text { Beam Diameter in } \\
\text { the focal position }\end{array}$ \\
\hline $\mathrm{f}_{\mathrm{f}}=300 \mathrm{~mm}$ & $0.74 \mathrm{~mm}$ \\
\hline $\mathrm{f}_{\mathrm{f}}=400 \mathrm{~mm}$ & $0.95 \mathrm{~mm}$ \\
\hline $\mathrm{f}_{\mathrm{f}}=500 \mathrm{~mm}$ & $1.18 \mathrm{~mm}$ \\
\hline $\mathrm{f}_{\mathrm{f}}=680 \mathrm{~mm}$ & $1.61 \mathrm{~mm}$ \\
\hline $\mathrm{f}_{\mathrm{f}}=1000 \mathrm{~mm}$ & $2.35 \mathrm{~mm}$ \\
\hline
\end{tabular}

The focal position and the beam diameter for the different lenses used were determined using a Primes $\mathrm{GmbH}$ Focus monitor system. A typical beam profile is shown in Figure 1 , indicating that the beam had a 'top-hat' profile. The laser power was calibrated using an Ophir Laser Meter; model 20K-W.

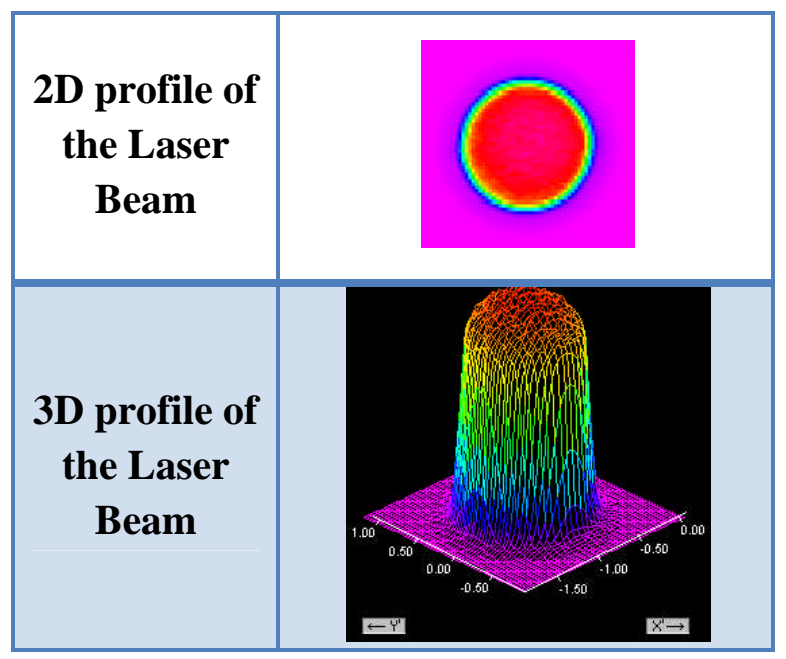

Figure 1 - 2D and 3D profile of the laser beam of the $\mathrm{cw}$ laser with a focussing lens of $\mathrm{f}_{f}=500$ $\mathrm{mm}$

The experiments were carried out by increasing the laser power and maintaining a constant beam diameter. This increased the power density whilst maintaining a constant interaction time. For different interaction times the beam diameter was also maintained constant and the travel speed was changed in order to obtain the values required.

The material used was S355 mild steel $12 \mathrm{~mm}$ thick. The plates were cleaned using a wire brush and then with acetone in order to avoid organic contamination of the welds. The chemical composition of the S355 mild steel is presented in Table 2. For the metallographic preparation all the samples were mounted, polished and etched using Nital $2 \%$.

Table 2 - Chemical composition of S355 mild steel

\begin{tabular}{|c|c|c|c|c|c|}
\hline \multicolumn{6}{|c|}{ Element (wt\%) S355 mild steel } \\
\hline $\mathrm{C}$ & $\mathrm{Si}$ & $\mathrm{Mn}$ & $\mathrm{Cr}$ & $\mathrm{Ni}$ & $\mathrm{Cu}$ \\
\hline Max & $0.25 /$ & $1.00 /$ & $\mathrm{Max}$ & $\mathrm{Max}$ & Max \\
0.15 & 0.55 & 1.65 & 0.25 & 0.45 & 0.3 \\
\hline
\end{tabular}

\section{Results}

The current definition of conduction and keyhole made based on a single power density value, independent of beam diameter or interaction time, was tested. Figure 2 shows an example of welds made at a lower power density than the $1 \mathrm{MW} / \mathrm{cm}^{2}$ but that have a keyhole weld profile, due to the high aspect ratio of the welds and the presence of undercut[7, 24, 25]. 

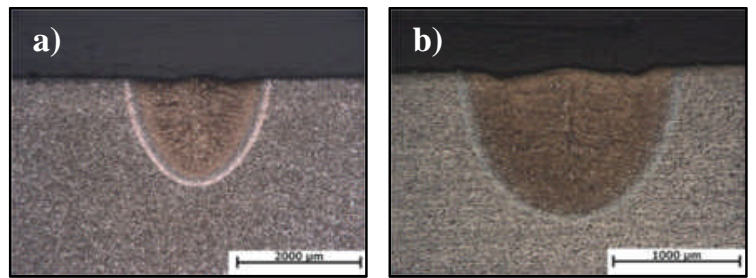

Figure 2 - a) macrographs of a weld produced with interaction time $=40 \mathrm{~ms}$, beam diameter $=0.95 \mathrm{~mm}$ and power density $=0.277$ $\mathrm{MW} / \mathrm{cm}^{2}$ b) macrograph of a weld produced with interaction time $=32 \mathrm{~ms}$, beam diameter= $0.95 \mathrm{~mm}$ and power density $=0.265 \mathrm{MW} / \mathrm{cm}^{2}$

The influence of increasing the power density with a constant interaction time and beam diameter was analysed. Figure 3 shows how the penetration depth changes with the power density for a constant beam diameter of $0.95 \mathrm{~mm}$ and a constant interaction time of $10 \mathrm{~ms}$. For each interaction time and beam diameter it was possible to fit a fourth order equation, with a $R^{2}$ of 0.99 , and to identify two inflection points. Combining the evaluation of the first inflection point with a visual analysis of the weld profiles it was possible to identify the power density that separates the conduction mode regime from the transition regime. This power density represents the upper limit of conduction mode, $\mathrm{Pd}_{\mathrm{CML}}$. An evaluation of the power density influence on penetration depth for different interaction times and different beam diameters allowed for the identification of the $\mathrm{Pd}_{\mathrm{CML}}$, i.e. the maximum power density allowed to do a conduction weld for a certain interaction time and beam diameter. Based on this three different modes can be identified: conduction mode, transition mode and keyhole mode.

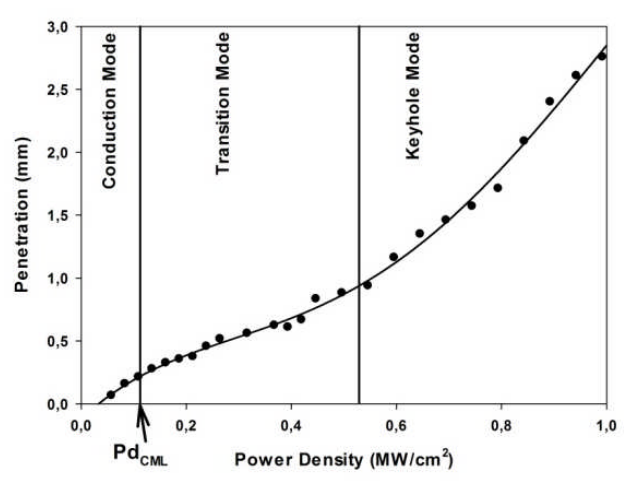

Figure 3 - Penetration depth versus power density for an interaction time of $10 \mathrm{~ms}$ and a beam diameter of $0.95 \mathrm{~mm}$

Similar behaviour was observed when using a different interaction time. Figure 4 shows the behaviour of the penetration depth with power density for an interaction time of 20 $\mathrm{ms}$ and a beam diameter of $0.95 \mathrm{~mm}$.

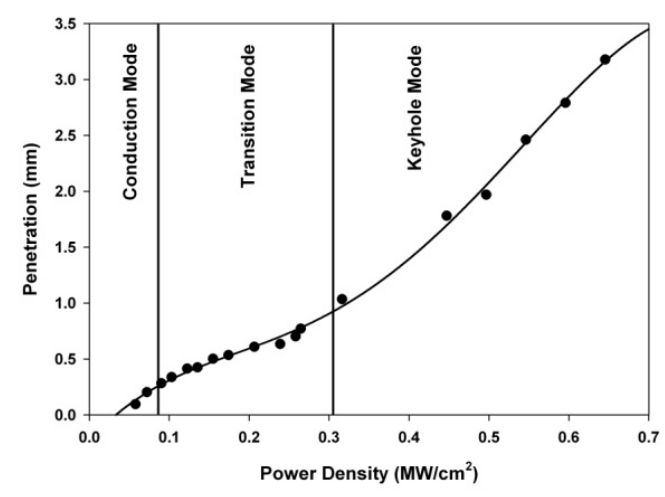

Figure 4 - Penetration depth versus power density for an interaction time of $20 \mathrm{~ms}$ and a beam diameter of $0.95 \mathrm{~mm}$

The same three modes are present for different beam diameters. Figure 5 shows the behaviour of penetration depth with power density for an interaction time $10 \mathrm{~ms}$ and a beam diameter of $1.18 \mathrm{~mm}$. 


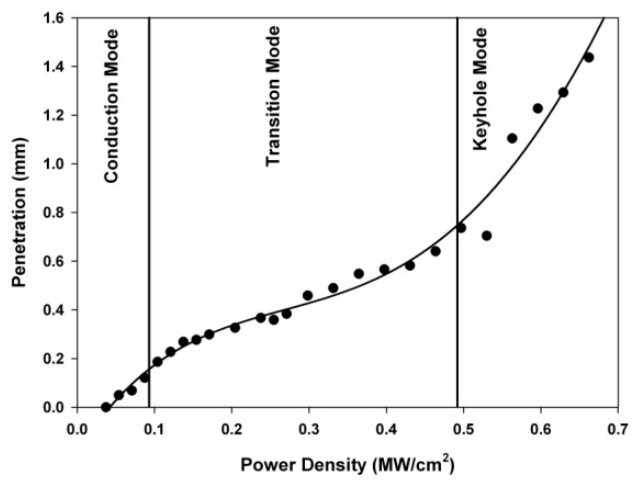

Figure 5 - Penetration depth versus power density for an interaction time of $10 \mathrm{~ms}$ and a beam diameter of $1.18 \mathrm{~mm}$

Figure 6 shows the relationship between the $\mathrm{Pd}_{\mathrm{CML}}$ and interaction time for different beam diameters. As the interaction time increases with a constant beam diameter, the $\mathrm{Pd}_{\mathrm{CML}}$ decreases.

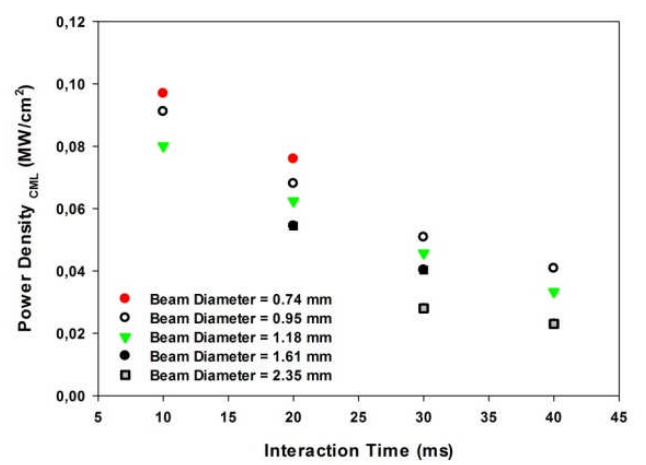

Figure 6 - Variation of the $P d_{C M L}$ with interaction time for different beam diameters

The relation between the $P d_{C M L}$ and the beam diameter for different interaction times is shown in Figure 7. It shows that, at a constant interaction time, the $\mathrm{Pd}_{\mathrm{CML}}$ decreases with the increase in the beam diameter.

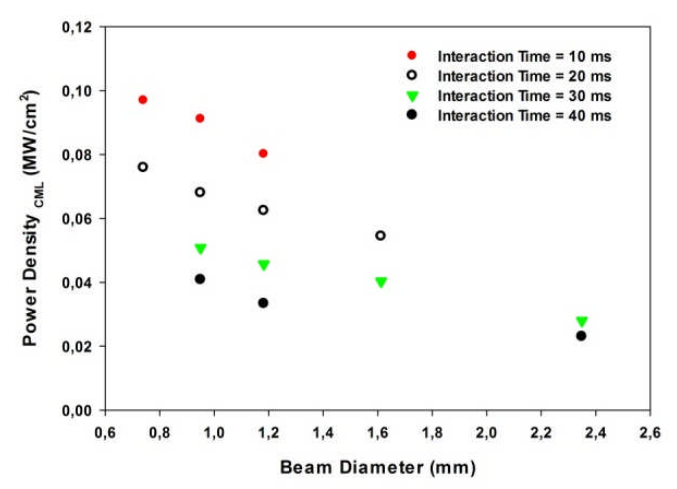

Figure 7 - Variations of the $P d_{C M L}$ with beam diameter for different interaction times

Figure 8 shows how the weld profile changes from a conduction mode weld to a weld done in the transition mode. The difference of the profile before and after the $P d_{C M L}$ can be seen. While the weld done below the limit presents a conduction profile, shallow welds with a small aspect ratio and a very flat top profile. The weld done in the transition mode starts to show some characteristics of keyhole mode, like undercut, a not so flat top profile and a small depression at the surface. However it also has small aspect ratio which is characteristic of conduction mode.

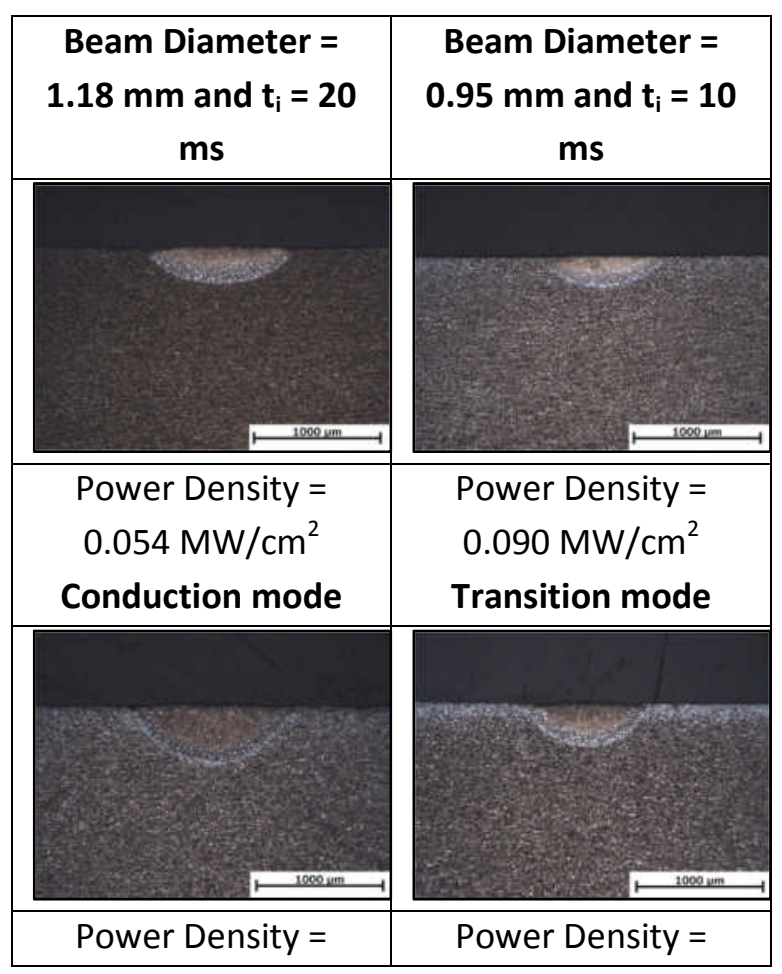




\begin{tabular}{|c|c|}
\hline $\begin{array}{l}0.087 \mathrm{MW} / \mathrm{cm}^{2} \\
\text { Transition mode }\end{array}$ & $\begin{array}{l}0.122 \mathrm{MW} / \mathrm{cm}^{2} \\
\text { Transition mode }\end{array}$ \\
\hline $12000 \mathrm{vm}$ & 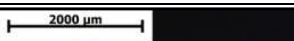 \\
\hline Power Density = & Power Density = \\
\hline $0.662 \mathrm{MW} / \mathrm{cm}^{2}$ & $0.992 \mathrm{MW} / \mathrm{cm}^{2}$ \\
\hline Keyhole mode & Keyhole mode \\
\hline
\end{tabular}

Figure 8 - Macrographs of welds done in conduction mode, transition mode and keyhole mode

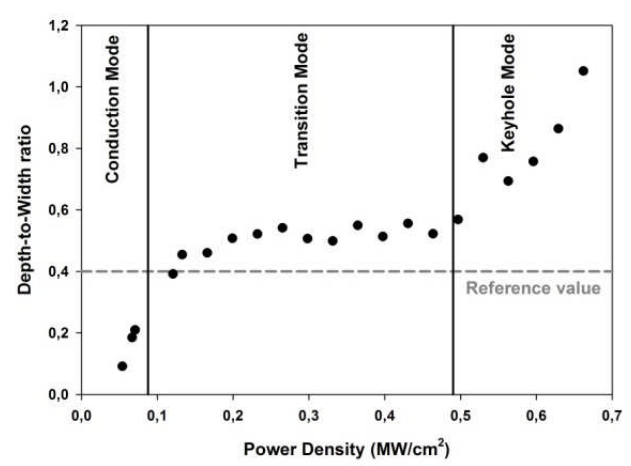

Figure 9 - Variation of the aspect ratio with the power density for beam diameter $=1.18$

$\mathrm{mm}$ and interaction time $=20 \mathrm{~ms}$

Figure 9 shows how the aspect ratio changes with the power density, for a beam diameter of $1.18 \mathrm{~mm}$ and interaction time of $20 \mathrm{~ms}$, it also shows the three distinct modes. This is also visible at different interaction time, Figure 9 and Figure 10. The dotted lines, shown in both figures, represent the aspect ratio of 0.4 which normally is used to separate conduction mode from keyhole mode[23].

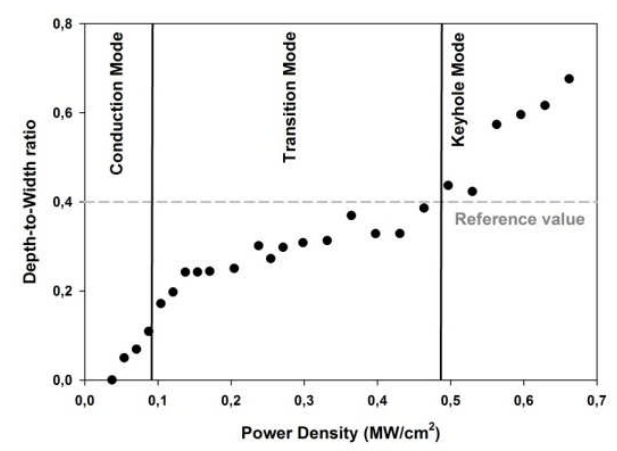

Figure 10 - Variation of the aspect ratio with the power density for beam diameter $=1.18$ $\mathrm{mm}$ and interaction time $=10 \mathrm{~ms}$

This shows that the use of the aspect ratio value to identify the welding mode is possible. During the transition mode the aspect ratio is almost constant, so this means that under this aspect ratio the weld will be in conduction mode while if the aspect ratio is higher the weld will be in keyhole mode. However the value of the ratio is not constant and it depends on the interaction time, Figure 11.

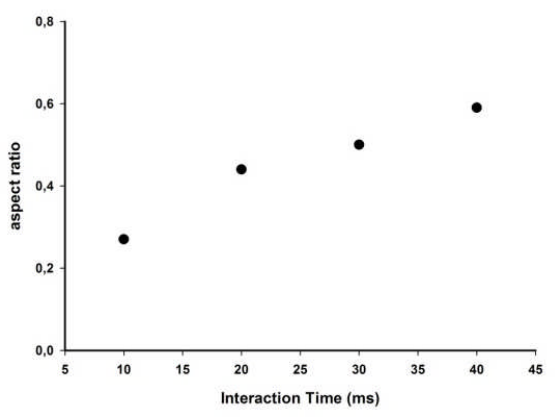

Figure 11 - Variation of the threshold aspect ratio with the interaction time for a beam diameter of $1.18 \mathrm{~mm}$

\section{Discussion}

The current definition of conduction mode and keyhole mode based on a single power density value, completely independent of other process parameters is inadequate. Also the switch between conduction mode and keyhole mode is not a sharp effect. There is a transition mode between these two welding modes, as shown by Figure 3, Figure 4 and 
Figure 5. This transition mode is characterized by having a slower increase of the penetration depth with the increase of power density when compared to the penetration depth increase with power density in conduction and keyhole mode. The welds obtained in this mode have some similarity with the keyhole mode (mainly the presence of some undercut, a not flat top profile and a small depression at the surface). Jay Lee et al[26] also observed the existence of a transition mode between conduction and keyhole mode based on a numerical simulation that has the evaporation recoil pressure as the driving pressure for keyhole formation and the surface tension and hydrostatic pressure as the opposing pressures for keyhole formation. In this work some speculation related to the power level where the transition takes place was made but no real correlation with the process parameters and the beginning of the transition mode, which is the end of the conduction mode, was made. Also no explanation as to the slow increase of the penetration with power density, in the transition mode, was given[26]. However, based on this model, the presence of this transition mode might be related to a balance between the pressures that oppose the formation of the keyhole and to the pressures that helps in the formation.

This transition mode might be caused by a region where the pressure generated by vaporization is too low to overcome the surface tension. This prevents the formation of a significant keyhole. During this mode most of the extra energy when increasing the power density is used in vaporising more material until a significant keyhole is formed. Hence there is only a small increase in penetration depth in the transition mode. A schematic of this behaviour is shown in Figure 12.

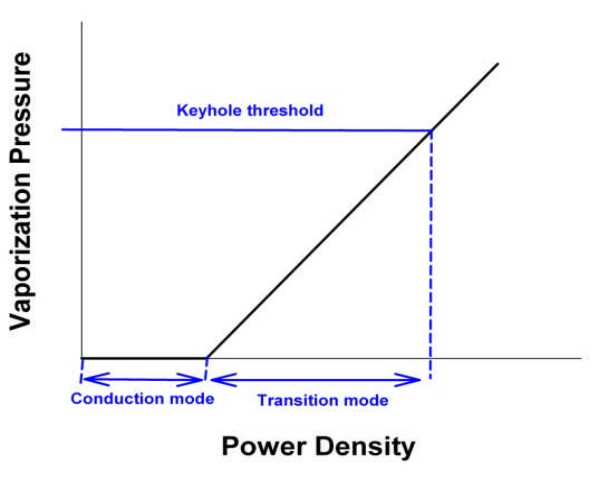

Figure 12 - Vaporization pressure versus power density

It was also observed that the beam diameter and interaction time have an effect on the $P d_{C M L}$ as shown in Figure 6 and Figure 7. The interaction time has a linear relationship with this power density limit. As the interaction time increases the $P d_{C M L}$ decreases, Figure 6 . This can be explained by the specific point energy. At a constant beam diameter the $\mathrm{Pd}_{\mathrm{CML}}$ decreases with the increase of interaction time. This is because as the interaction time of the laser beam increases, less energy is necessary to change from a conduction mode to a transition mode. For a constant interaction time the $\mathrm{Pd}_{\mathrm{CML}}$ decreases with an increase of beam diameter, Figure 7 . This effect of the beam diameter on this limit can also be explained by the specific point energy rather than power density. At a constant interaction time the $\mathrm{Pd}_{\mathrm{CML}}$ increases with the increase of the beam diameter. This is because as the area of interaction with the laser beam is increased, more energy is necessary to change from a conduction mode to a transition mode.

The evaluation of the welding regime based on the aspect ratio is also possible. The transition mode shows a constant aspect ratio, while conduction mode and the keyhole mode show a linear increase of the ratio with power density, Figure 9 and Figure 10 . Therefore if the weld has an aspect ratio 
lower than the one observed in the transition mode the weld is in conduction mode. However, if the aspect ratio value is higher than the weld is in keyhole mode. In transition mode the extra energy just vaporizes more material so the aspect ratio value remains almost constant. However the aspect ratio value that separates conduction mode from keyhole mode is dependent on the interaction time, rather than being a constant single value, Figure 11.

\section{Conclusions}

In laser welding there is not a sharp transition between conduction mode and keyhole mode but a transition mode where the rate of increase of the penetration depth with power density is reduced.

The welds obtained in the transition mode show characteristics of the other two welding modes like undercut, a not flat top profile and a small depression at the surface, which are characteristic of keyhole mode, and a low aspect ratio, characteristic of conduction mode.

The $P d_{C M L}$ is dependent on the interaction time and on beam diameter. The increase of the interaction time results in the decrease of the $P d_{C M L}$. While the increase of the beam diameter results in a decrease of the $P d_{C M L}$.

The aspect ratio can be used to distinguish between conduction mode and keyhole mode. However the aspect ratio value that separates conduction mode from keyhole mode is dependent on the interaction time used.

It was also shown how the use of the fundamental material interaction parameters of interaction time and power density and also specific point energy as process parameters allows a good understanding of the results obtained.

\section{References}

1. Steen, W.M., Laser material processing. 3rd ed. ed. 2003, New York ; London: Springer. $448 \mathrm{p}$.

2. Kawahito, Y., M. Mizutani, and S. Katayama, High quality welding of stainless steel with $10 \mathrm{~kW}$ high power fibre laser. Science and Technology of Welding and Joining, 2009. 14(4): p. 288-294.

3. Ramasamy, S. and C.E. Albright, CO2 and Nd-YAG laser beam welding of 5754$O$ aluminium alloy for automotive applications. Science and Technology of Welding and Joining, 2001. 6(3): p. 182190.

4. Assuncao, E., L. Quintino, and R. Miranda, Comparative study of laser welding in tailor blanks for the automotive industry. International Journal of Advanced Manufacturing Technology. 49(1-4): p. 123-131.

5. Sanchez-Amaya, J.M., et al., Laser welding of $A A 5083$ samples by high power diode laser. Science and Technology of Welding and Joining, 2009. 14(1): p. 78-86.

6. Assuncao, E., et al., Conduction mode Broadening the range of applications for laser welding, in 63rd Annual Assembly \& International Conference of the International Institute of Welding. 2010: Istanbul, Turkey.

7. Morgan, S. and S. Williams, Hybrid laser conduction welding, in 55th Annual Assembly of International Institute of Welding. 2002: Copenhagen, Denmark.

8. Ready, J.F. and D.F. Farson, LIA handbook of laser materials processing. 2001, Orlando, Fla.: Laser Institute of America. xxv, 715 p.

9. Ion, J.C., Laser processing of engineering materials : principles, procedure and industrial application. 2005, Amsterdam ; Oxford: Elsevier/Butterworth-Heinemann. xviii, 556 p.: ill.; $26 \mathrm{~cm}$.

10. Sanchez-Amaya, J.M., et al., Laser welding of aluminium alloys 5083 and 6082 under conduction regime. Applied Surface Science, 2009. 255(23): p. 95129521.

11. Sibillano, T., et al., Optical detection of conduction/keyhole mode transition in laser welding. Journal of Materials Processing Technology, 2007. 191(1-3): p. 364-367.

12. Zhang, X., et al. Laser welding mode transition and influence of thermal focusing on mode transition. in Proceedings of SPIE - The International 
Society for Optical Engineering. 1996. Beijing, China.

13. Chen, W., X. Zhang, and J. Ren, Study of welding mode transition and stability of welding process in high laser welding. Chinese Journal of Lasers, 1996. 23(7).

14. Zhang, X., W. Chen, and J. Ren, Effects of processing parameters on mode and stability of laser welding, in Photonics West'96. 1996.

15. Reitemeyer, D., T. Seefeld, and F. Vollertsen. Online focus shift measurement in high power fiber laser welding. in 29th International Congress on Applications of Lasers and ElectroOptics, ICALEO 2010 - Congress Proceedings. Anaheim, CA.

16. Seefeld, T. Chances and challenges in processing with high brightness lasers. in 29th International Congress on Applications of Lasers and Electro-Optics, ICALEO 2010 - Congress Proceedings. Anaheim, CA.

17. Buvanashekaran, G., et al., A study of laser welding modes with varying beam energy levels. Proceedings of the Institution of Mechanical Engineers, Part C: Journal of Mechanical Engineering Science, 2009. 223(5): p. 1141-1156.

18. Colegrove, P., et al. Evaluation of $a$ drilling model approach to represent laser spot microwelding. in ASM Proceedings of the International Conference: Trends in Welding Research. 2009. Pine Mountain, GA.

19. Ahmed, N., New Developments in Advanced Welding. 2005: CRC Press.

20. Dasgupta, A.K. and J. Mazumder, Laser welding of zinc coated steel: An alternative to resistance spot welding. Science and Technology of Welding and Joining, 2008. 13(3): p. 289-293.

21. Semak, V.V., G.A. Knorovsky, and D.O. MacCallum, On the possibility of microwelding with laser beams. Journal of Physics D: Applied Physics, 2003. 36(17): p. 2170-2174.

22. Resch, M. and A.F.H. Kaplan, Heat conduction modelling of laser welding. Lasers in Engineering, 1998. 7(3-4): p. 229-240.

23. Weckman, D.C., H.W. Kerr, and J.T. Liu, The effects of process variables on pulsed Nd:YAG laser spot welds: Part II. AA 1100 aluminum and comparison to AISI 409 stainless steel. Metallurgical and Materials Transactions B: Process Metallurgy and Materials Processing Science, 1997. 28(4): p. 687-700.
24. Nakamura, S., et al., Detection technique for transition between deep penetration mode and shallow penetration mode in CO2 laser welding of metals. Journal of Physics D: Applied Physics, 2000. 33(22): p. 2941-2948.

25. Bardin, F., et al., Process control of laser conduction welding by thermal imaging measurement with a color camera. Applied Optics, 2005. 44(32): p. 68416848.

26. Lee, J.Y., et al., Mechanism of keyhole formation and stability in stationary laser welding. Journal of Physics D: Applied Physics, 2002. 35(13): p. 1570-1576. 